\title{
Endoscopic extraction of a gastric submucosal foreign body after precise location with endoscopic ultrasound combined with endoscopic submucosal dissection
}

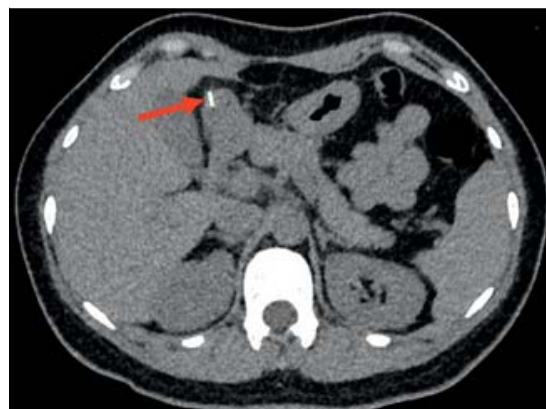

- Fig. 1 Computed tomography scan showing an 18-mm high density shadow in the gastric antrum (red arrow), consistent with suspected penetration of the gastric wall.



- Fig. 2 Gastroscopic image showing no obvious foreign body and no evidence of mucosal damage or bleeding.
A 34-year-old woman was referred to the emergency department of our hospital with persistent epigastric pain for 2 days. Abdominal computed tomography (CT) scanning showed an $18-\mathrm{mm}$ high density shadow in the gastric antrum, consistent with suspected penetration of the gastric wall ( $\triangleright$ Fig.1). Gastroscopy however showed no obvious foreign body ( Fig.2). The patient was still suffering from abdominal pain. We speculated that a foreign body might have completely imbedded into the submucosa or even the gastric serosal layer, which would make it more difficult to detect.
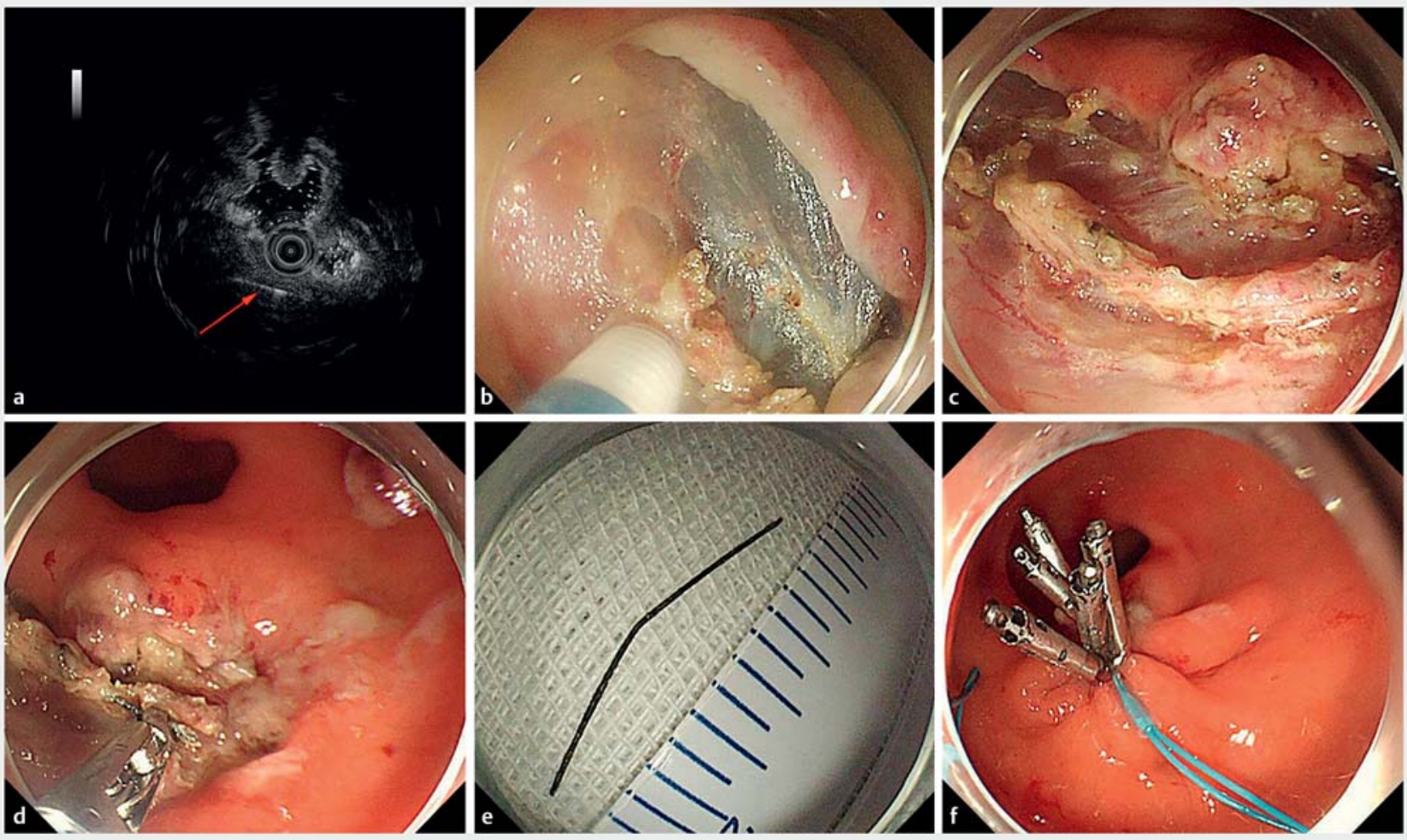

- Fig. 3 Images from the procedure showing: a a cordlike hyperechoic shadow in the submucosa of the gastric antrum (red arrow) being precisely located and marked using endoscopic ultrasound; $\mathbf{b}-\mathbf{d}$ endoscopic images of: $\mathbf{b}$ the submucosa and muscularis being carefully separated with a FlushKnife; $\mathbf{c}$ an iron wire that was deeply imbedded in the muscularis; $\mathbf{d}$ the iron wire being carefully clamped with a foreign body forceps; e a photograph of the iron wire foreign body after its successful removal; $\mathbf{f}$ endoscopic appearance of the wound after closure with endoscopic clips. 


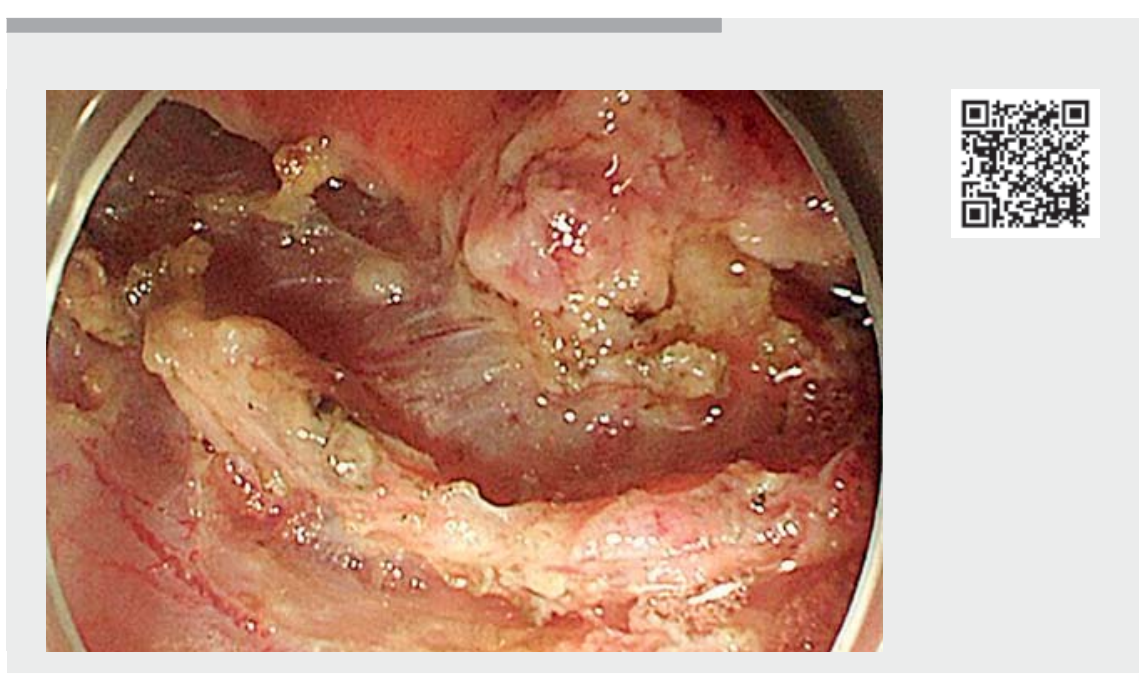

$\checkmark$ Video 1 Endoscopic extraction of a gastric submucosal foreign body after its precise location using endoscopic ultrasound combined with endoscopic submucosal dissection.

We therefore proceeded to endoscopic ultrasound (EUS) and found a cordlike hyperechoic shadow in the submucosa of the gastric antrum ( $\vee$ Fig. $\mathbf{3}$ a). Because there was a risk of perforation if the foreign body was not removed in a timely fashion, a special endoscopic operation was immediately arranged for the patient.

Endoscopic submucosal dissection (ESD) is regarded as a common treatment for complete resection of early gastrointestinal neoplasms [1]. ESD-assisted removal of a submucosal foreign body in the stomach has rarely been reported [2]. After the lesion had been precisely located and marked using EUS, the submucosa and muscularis were carefully separated with a FlushKnife (Fujifilm)

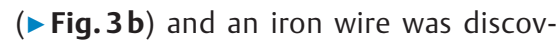
ered that was deeply imbedded into the muscularis ( $\mathbf{F i g . 3 c}$ ). The iron wire was carefully clamped with a foreign body forceps (Olympus) and gently pulled out ( $\triangleright$ Fig.3 d,e; $>$ Video 1 ). The wound was closed with endoscopic clips and no bleeding was observed ( $\mathbf{F i g . 3 f}$ ). The patient was discharged from hospital after 2 days of observation.

Buried submucosal foreign bodies in the stomach, although very rare, can cause serious complications. Endoscopic extraction of a gastric submucosal foreign body with precise location by EUS combined with ESD is safe and avoided the risks of major surgery, thereby minimizing trauma and economic losses.

\section{Endoscopy_UCTN_Code_TTT_1AO_2AL}

\section{Competing interests}

The authors declare that they have no conflict of interest.

The authors

Yuqing Mao*, Bin Hu*, Xiaoyuan Gong, Shengzheng Luo, Youchen Xia, Chenghong Fu, Baiwen Li

Department of Gastroenterology, Shanghai General Hospital, Shanghai Jiao Tong University School of Medicine, Shanghai, China

\section{Corresponding author}

\section{Baiwen Li, MD}

Department of Gastroenterology, Shanghai General Hospital, Shanghai Jiao Tong University School of Medicine, New Songjiang Road No. 650, Shanghai 200080 , China

muzibowen@126.com

\section{References}

[1] Ono H, Yao K, Fujishiro M et al. Guidelines for endoscopic submucosal dissection and endoscopic mucosal resection for early gastric cancer (second edition). Dig Endosc 2021; 33: 4-20

[2] Cheng NM, Yip HC, Chan SM et al. Endoscopic removal of a submucosal embedded foreign body in the duodenum. Endoscopy 2020; 52: E353-E354

\section{Bibliography}

Endoscopy 2022; 54: E415-E416

DOI 10.1055/a-1559-2250

ISSN 0013-726X

published online 8.9.2021

(c) 2021. Thieme. All rights reserved.

Georg Thieme Verlag KG, Rüdigerstraße 14,

70469 Stuttgart, Germany

\section{ENDOSCOPY E-VIDEOS \\ https://eref.thieme.de/e-videos}

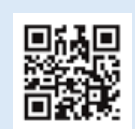

Endoscopy E-Videos is an open access online section, reporting on interesting cases and new techniques in gastroenterological endoscopy. All papers include a high quality video and all contributions are freely accessible online. Processing charges apply (currently EUR 375), discounts and wavers acc. to HINARI are available.

This section has its own submission website at https://mc.manuscriptcentral.com/e-videos

\footnotetext{
${ }^{*}$ Contributed equally to this manuscript
} 